\title{
THE EFFECT OF TESTOSTERONE COMPOUNDS UPON THE NITROGEN BALANCE AND CREATINE EXCRETION IN PATIENTS WITH THYROTOXICOSIS 1, 2
}

\author{
By LAURENCE W. KINSELL, ${ }^{3}$ SAUL HERTZ, AND EDWARD C. REIFENSTEIN, JR. \\ (From the Medical Service and the Thyroid Clinic of the Massachusetts General Hospital \\ and the Department of Medicine of the Harvard Medical School, Boston)
}

(Received for publication February 7, 1944)

The tendency to increased urinary nitrogen excretion in thyrotoxicosis has been well demonstrated ( 1 to 5$)$. The presence of hypercreatinuria in thyrotoxicosis has recently been reviewed and confirmed $(6,7)$.

In view of the constancy of these two findings, and their importance in the pathologic physiology of Graves' disease, it seemed reasonable to postulate that an agent which would tend to reverse or inhibit both of these processes, might have some beneficial effect upon the disease. Testosterone propionate has been shown to exert a proteinanabolic and a creatine-retaining effect in animals (8) and in individuals with other clinical syndromes (9 to 12). It has also been shown to reduce the creatinuria of experimentally induced hyperthyroidism of monkeys (13).

Methyl testosterone, like testosterone propionate, causes protein anabolism but, unlike testosterone propionate, causes extreme creatinuria (14). Furthermore, methyl testosterone has been reported to exert a significant calorigenic effect, in contrast to testosterone propionate, which has little or no action of this kind $(8,9,15$, 16).

We were interested, therefore, in determining the effects of these two compounds upon the nitrogen and the creatine excretion, and upon the clinical status of patients with thyrotoxicosis.

\footnotetext{
1 The expense of these studies was partly defrayed by grants from the Josiah Macy, Jr. Foundation, the National Research Council (Committee for Research in the Problems of Sex), and from the H. N. C. Gift, Harvard University.

2 Acknowledgment is made to the Schering Corporation of Bloomfield, New Jersey, for the generous supplies of testosterone propionate (Oreton) and of methyl testosterone (Oreton-M) used in this investigation.

3 Research Fellow in Pharmacotherapy.
}

\section{MATERIALS AND METHODS}

Studies on 3 thyrotoxic patients are reported in this paper. All of the patients were stabilized before the metabolic studies were begun upon a diet that was higher in protein, calories, and vitamins than the usual requirements of normal individuals. This diet was maintained throughout the period of observation. Activity was kept at an approximately constant level throughout the experimental period.

Urinary nitrogen was determined by the microKjeldahl method on aliquots of 3-day pools. The nitrogen content of the stool was considered to be one-tenth of the intake. This assumption was checked in one patient during the period of greatest nitrogen retention, and found to be essentially correct. Urinary creatine and creatinine were determined every third day, on an aliquot of that day's specimen (17). Excretion of 17-ketosteroids was determined on aliquots of 3-day urine pools by a modification (18) of the original method. The basal metabolic rate was determined at frequent intervals, using the Dubois standard. Body weight was recorded at least once during each 3-day period. Serum constituents were determined by standard laboratory procedures.

After a suitable number of control periods, the patients were given courses of varying amounts of testosterone propionate intramuscularly or methyl testosterone, orally. The former was employed in a concentration of $25 \mathrm{mgm}$. per ml. of sesame oil; the latter in tablets, each containing $10 \mathrm{mgm}$. of the steroid.

With the exception of patient P. C. (Case 3), none of the patients reported in this series had received iodine at any time prior to the period of metabolic study.

\section{RESULTS}

Case 1, M. M., U 362811 (Lab. $\$ 23209$ ), an unmarried female, aged 28 , gave a 2 -months history of increasing weight loss in spite of a goodly food intake, sweating, palpitation, and nervousness. Her menstrual history was normal. Physical findings included a moderately prominent, diffusely enlarged thyroid gland, with bilateral thrill and bruit. There was little or no exophthalmos, and no other eye signs. Her skin was moist and flushed; she had a definite tremor, and was generally hyperreactive. The mean of two basal metabolic rates, done before the institution of therapy, was +35 per cent. The metabolic and other data obtained on this patient are shown in Figure 1. 


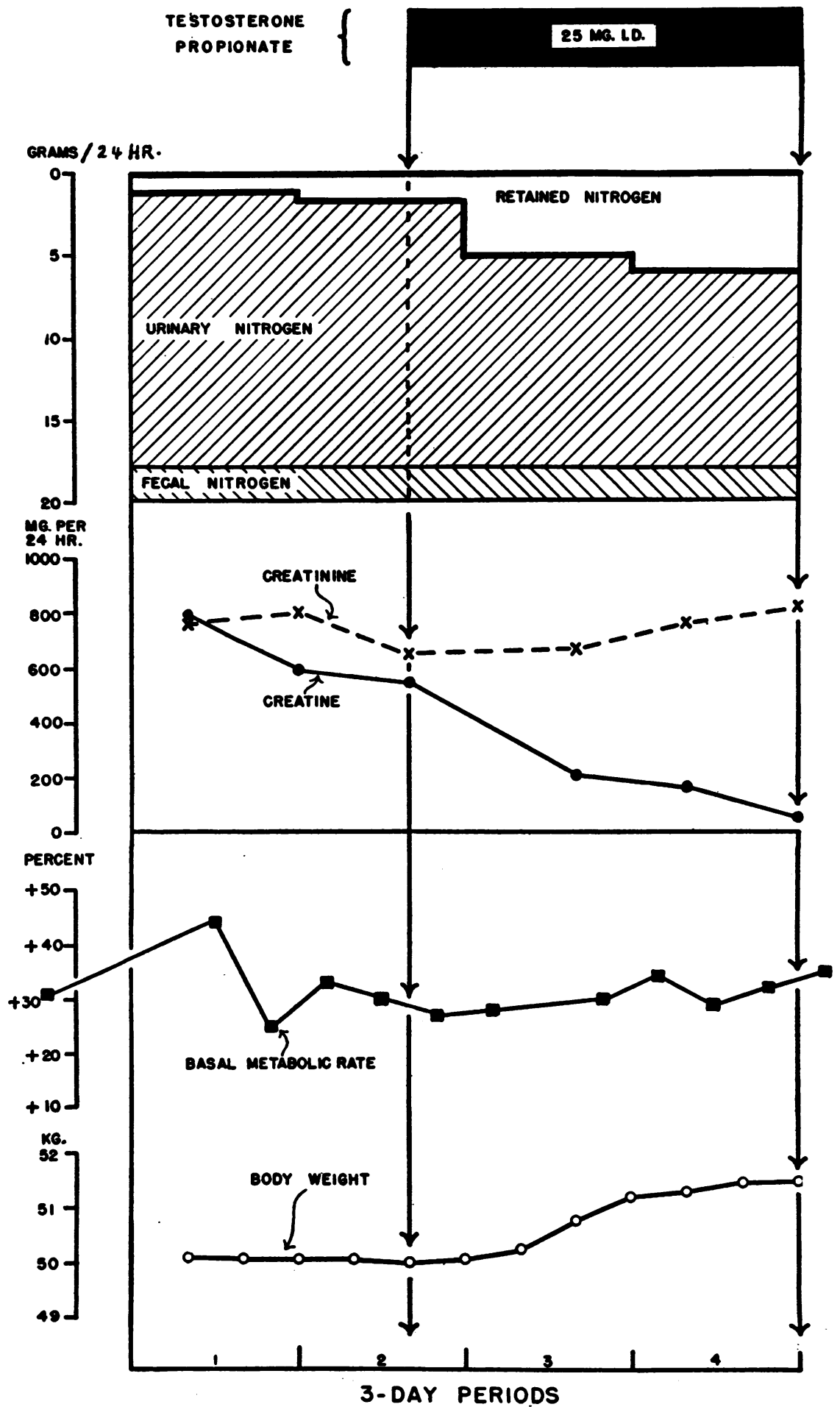

Fig. 1. Effect of Testosterone Propionate on Patient M. M. (Case 1)

In this and subsequent charts, nitrogen intake (protein -6.25) is represented by the interval between the " $O$ " line and the bottom line (in this case the "20" line). The fecal and urinary nitrogens are so labelled. If the line representing the summation of urinary and fecal nitrogen lies below the " $O$ " line, the individual is in positive balance. Correspondingly, if the output line rises above the " $O$ " intake level, the individual is in negative nitrogen balance. All metabolic data are reduced to values per 24 hours rather than per period. 


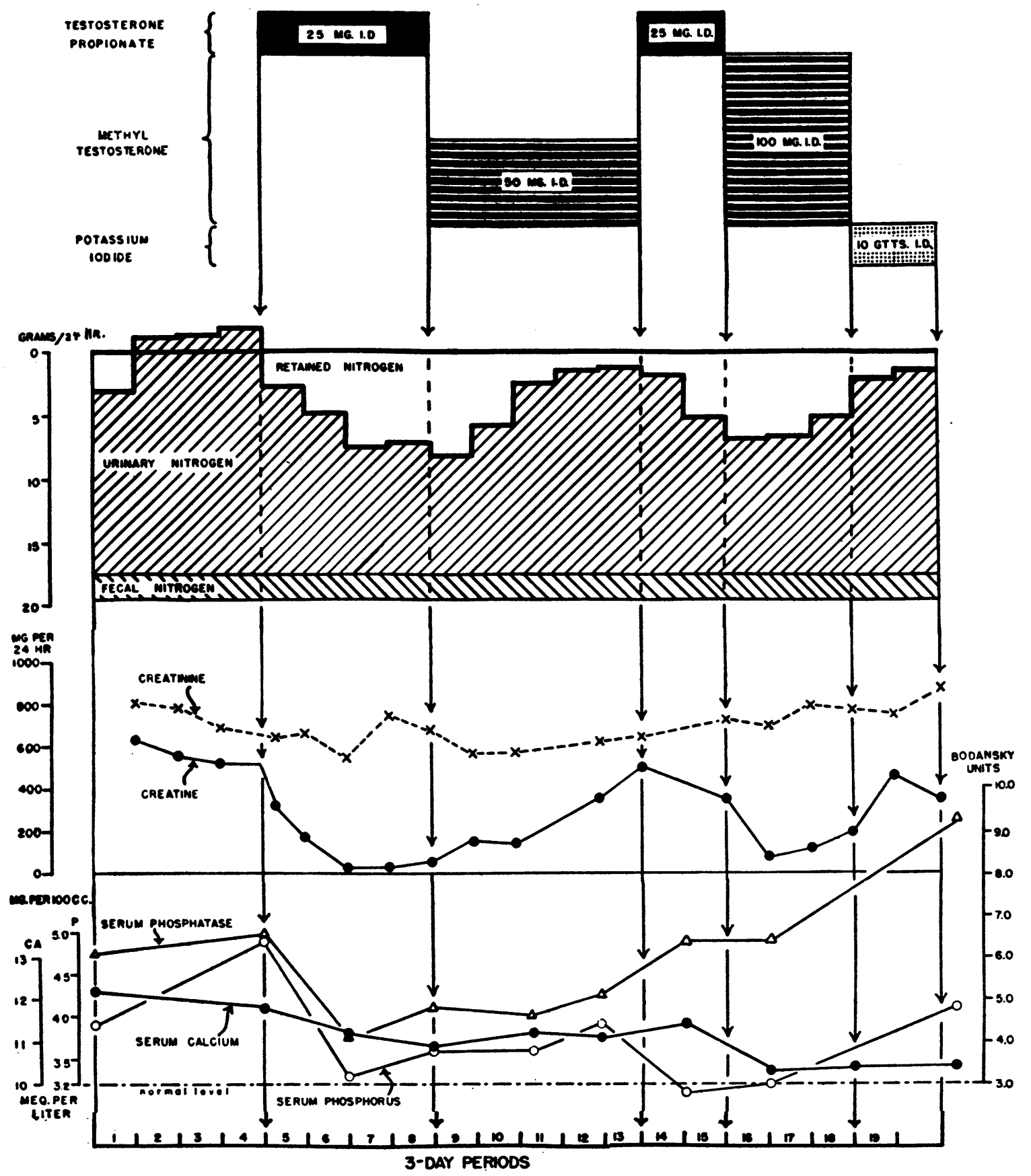

Fig. 2a. Effect of Testosterone Propionate and Methyl Testosterone on Patient H. L. (Case 2)

In spite of the brief control period in this patient, the increase in nitrogen retention, the gain in weight, and the decrease in creatinuria, induced by testosterone propionate therapy, are quite apparent. Her basal metabolic rate did not change significantly.

Case 2, H. L., U 369099 (Lab. $\$ 23307$ ), a schoolgirl, aged 14, gave a story of weight loss in spite. of a large food intake, rapid growth, nervousness, tremor, sweating, and quite marked enlargement of the neck of 1 year's duration. At the time of the metabolic study, the menses had not appeared, although pubic hair and breast development were present. One sister had been operated upon for hyperthyroidism at the age of 16 . Physical findings included a prominent, diffusely enlarged thyroid gland, 


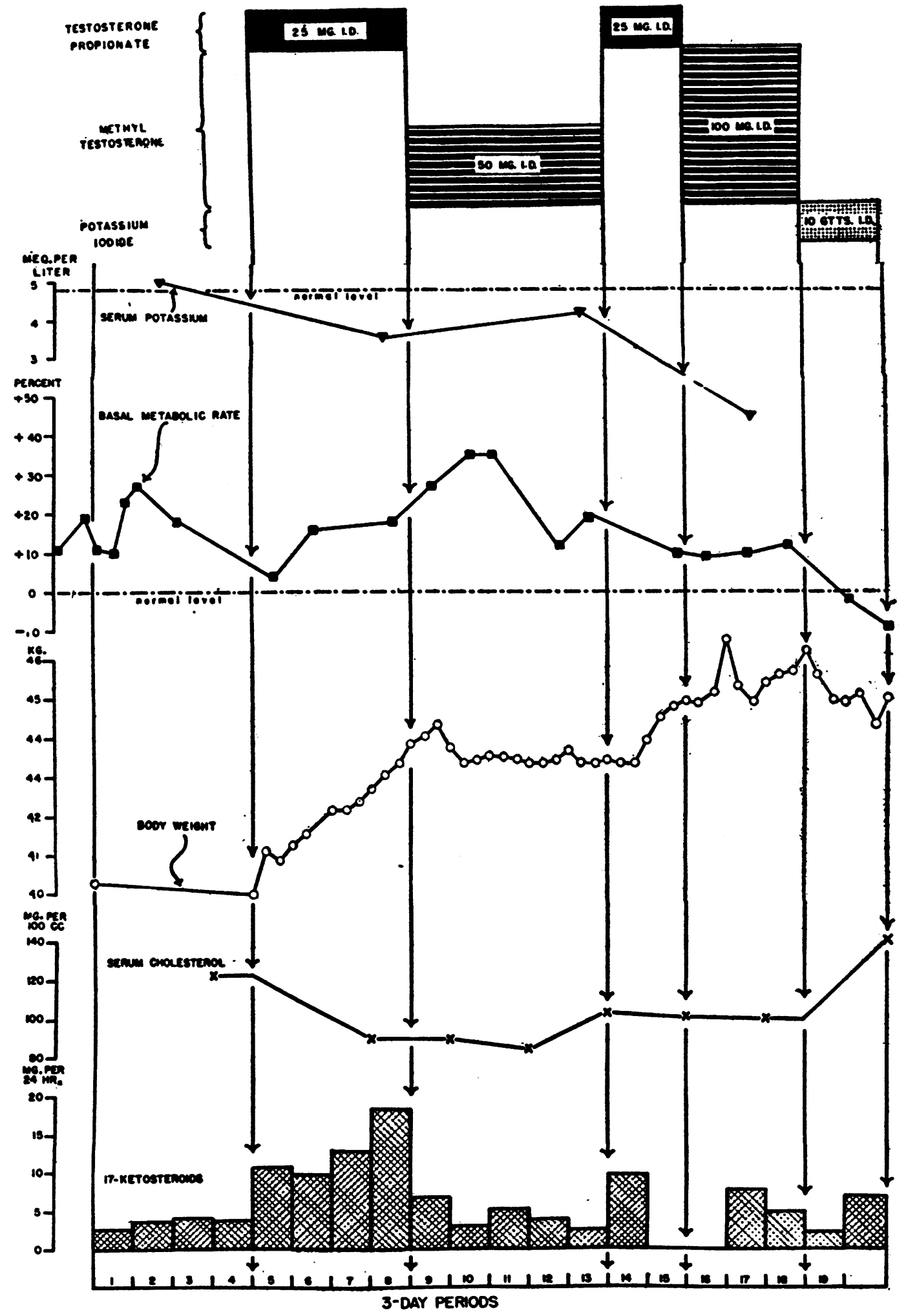

Fig. 2B. Case 2 contunued 
with bilateral thrill and bruit; slight exophthalmos without lid lag or disturbance in convergence; pulse rate of approximately 100 per minute. Fine tremors of tongue and hands and hyperkinesis in general were readily observable. Her palms were warm and moist. The mean of 7 pre-treatment basal metabolic rates was +17 per cent.

After stabilization upon the diet, her nitrogen and creatine excretions were determined for 4 periods, during which time she had extreme creatinuria, lost a little weight, but was approximately in nitrogen balance (Figures $2 \mathrm{~A}$ and $\mathrm{B}$ ). On testosterone propionate (25 mgm. daily), she retained progressively more nitrogen, gained weight, and put out decreasing quantities of creatine. With methyl testosterone ( $50 \mathrm{mgm}$. daily), her nitrogen balance became progressively less positive, she failed to gain weight, and excreted increasing amounts of creatine in the urine. There was a suggestion of an increase in the basal metabolic rate and clinically she became irritable and uncooperative. Testosterone propionate therapy was then resumed, with results almost identical with those obtained during the initial administration: marked nitrogen retention, rapid gain in weight, and decreased creatinuria. Following this, she received methyl testosterone, $100 \mathrm{mgm}$. daily, for 3 periods. The data indicate that this dosage of methyl testosterone had a less sustained effect upon the nitrogen retention than the $25 \mathrm{mgm}$. dosage of testosterone propionate. Furthermore, the larger dosage of methyl testosterone induced only a moderate gain in weight and increased the excretion of creatine. Clinically, she seemed much more toxic, but this finding was not reflected in the basal metabolic rate.

Steroid therapy was then stopped, and she was placed on potassium iodide. Her basal rate dropped immediately to minus levels, but in spite of this she retained progressively less nitrogen. (This "rebound" on the basis of our experience with other patients is probably much less than would have occurred had she received no potassium iodide.)

The serum calcium and phosphorus values, which had been somewhat elevated prior to therapy, tended to become normal during the administration of testosterone compounds. The serum phosphatase, which was moderately elevated prior to therapy, fell to normal levels during the initial period of testosterone propionate administration, but tended to rise during further treatment. The one value obtained during potassium iodide medication was elevated well above the pre-treatment level. The serum potassium dropped to subnormal levels during treatment.

The 17-ketosteroid excretion, which was relatively low prior to treatment for a girl of this age, increased during testosterone propionate administration (18), but dropped to pre-treatment levels with methyl testosterone. It is interesting that her last value while on potassium iodide was more than double her initial pre-treatment level.

Case 3, P. C., U 369235 (Lab. 23326), a 45-year-old male, gave a 9-months history of extreme weakness, nervousness, and weight loss despite a goodly food intake, and an almost lifelong history of emotional instability, tremor, and profuse perspiration. His thyroid gland was moderately enlarged. A bruit could be discerned on the right side. Exophthalmos was questionable; there was no lid lag, and but slight disturbance in convergence. A tremor of the hands and feet could be readily demonstrated. His skin was quite moist and warm. Before admission to the metabolic ward, he had received potassium iodide for 2 months, and had had a single oral administration of radioactive iodine two and one-half months previously. His basal metabolic rate on admission was +42 per cent. Since he was fully iodinized but definitely thyrotoxic, we continued him on potassium iodide throughout his metabolic studies.

We desired in this patient to determine the effects of different dosages of testosterone propionate, and of methyl testosterone, and particularly to discover the relative dosages of each required to produce a similar degree of protein anabolism. Also we wished to see whether the adverse clinical effects of methyl testosterone, previously noted on patient $H$. L. (Case 2), would be manifest in this patient.

He was placed, accordingly, on the following program: (1) 4 periods of no treatment (except potassium iodide) ; (2) 4 periods of $12.5 \mathrm{mgm}$. of testosterone propionate daily ; (3) 4 periods of $100^{\circ} \mathrm{mgm}$. of methyl testosterone daily; (4) 4 periods of $25 \mathrm{mgm}$. of testosterone propionate daily; (5) 4 periods of $50 \mathrm{mgm}$. of testosterone propionate daily; (6) 6 periods of $100 \mathrm{mgm}$. of testosterone propionate daily; and (7) 4 periods of no treatment (except potassium iodide).

The findings during these various regimes are shown in Figures $3 \mathrm{~A}$ and $\mathrm{B}$.

The findings on the previous patients were confirmed. Specifically, a very positive nitrogen balance was produced with testosterone propionate in all dosages used, and the degree of nitrogen retention was either increased or maintained at a constant level throughout the period of administration of the compound; methyl testosterone, on the other hand, while unquestionably causing nitrogen retention, failed to exert the sustained effect characteristic of testosterone propionate. Thus, the nitrogen balance became progressively less positive throughout the period of administration. In this patient, testosterone propionate completely stopped the excretion of creatine in the urine, while methyl testosterone caused a marked creatinuria. During the time that the patient received methyl testosterone, he became so toxic and unmanageable that we were tempted to discontinue the medication before the 4 periods were completed. Conversely, we felt that he received definite clinical benefit from the testosterone propionate administration. It should also be noted that he had been impotent for many months. Even with the very large dosage of androgens employed, no objective or subjective effects upon the genitalia were induced.

With the diet employed, he lost weight rapidly prior to testosterone propionate administration, but was 


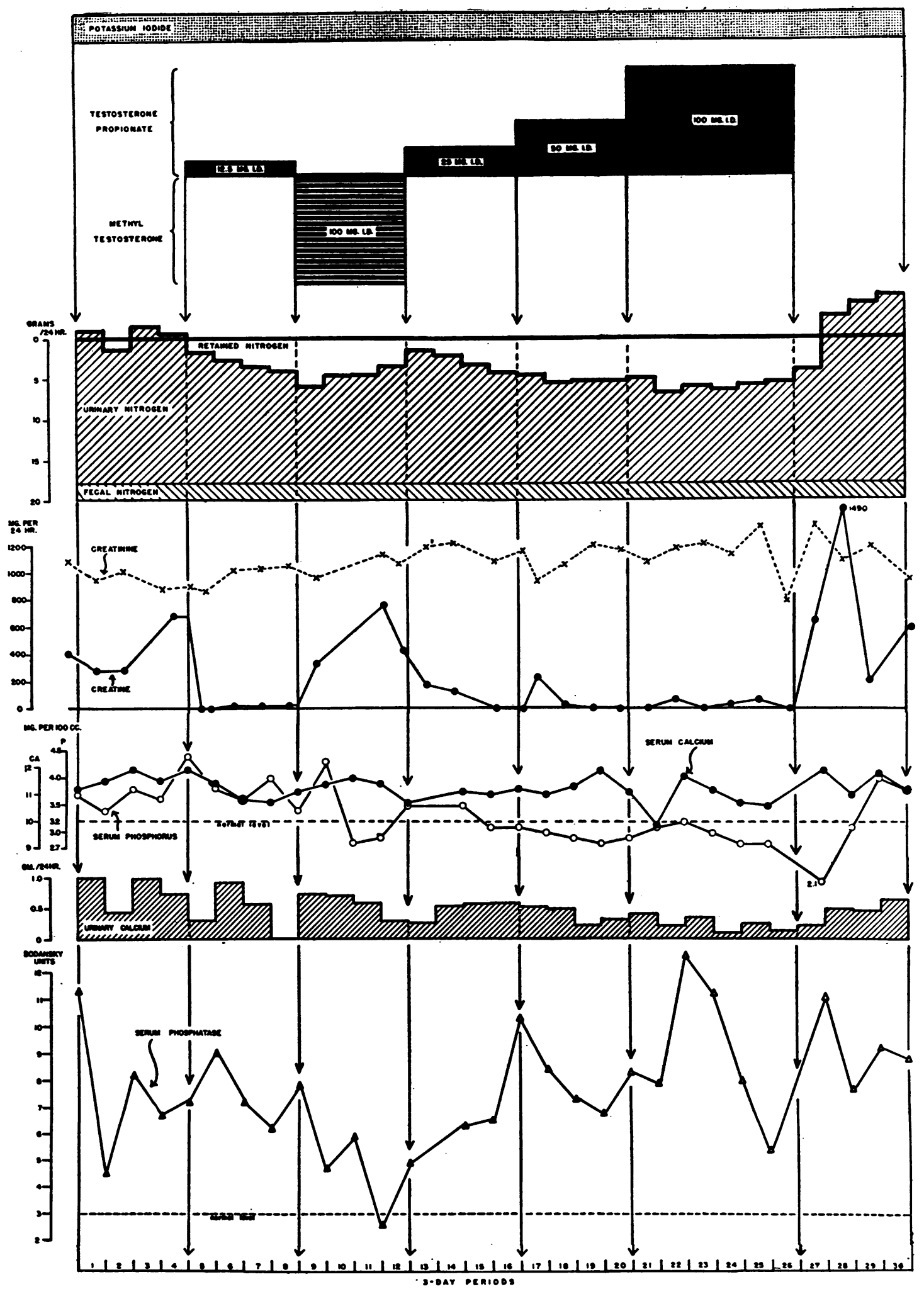

Fig. 3a. Comparative Effects of Testosterone Propionate and Methyl Testosterone on Thyrotoxic Patient P. C. (CASE 3)

Potassium iodide, gtts. 15, given daily throughout metabolic study. 


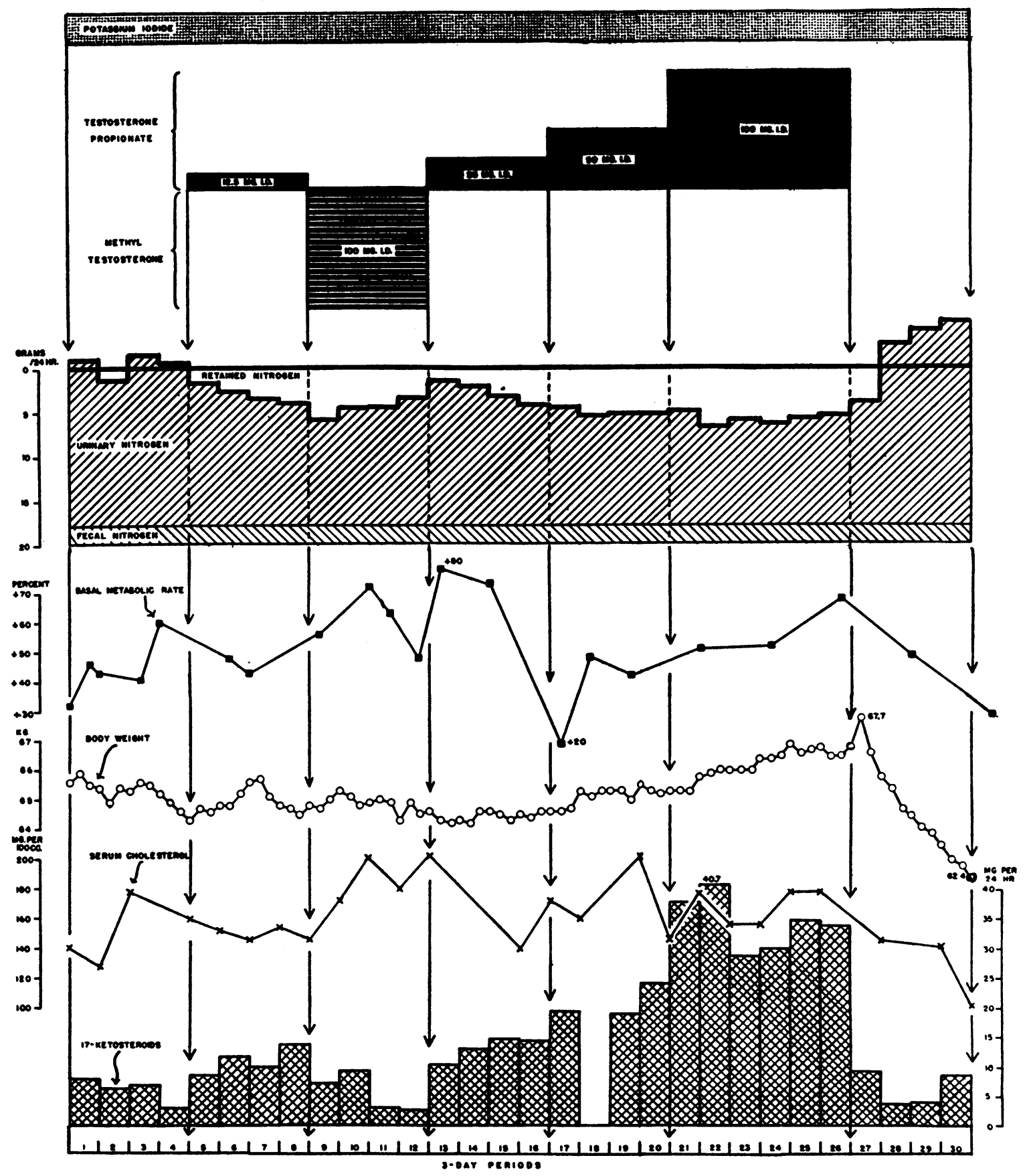

Fig. 3B. Case 3 continued

approximately in nitrogen balance. During the time that he received testosterone propionate and methyl testosterone, his weight remained fairly constant. Following cessation of testosterone-compound therapy, he went into a very negative nitrogen balance and showed a rapid weight loss and an intense creatinuria.

As in patient H. L. (Case 2), there was a tendency to depression of the serum calcium and inorganic phosphorus levels during the period of steroid administration. In the case of the latter element, the effect seemed to be proportional to the dosage employed. The serum phosphatase showed extreme degrees of fluctuation, the interpretation of which is not apparent. It fell to a normal value during methyl testosterone administration, but was more 
or less elevated at all other times. The serum cholesterol level showed no significant change.

The alterations observed in the 17-ketosteroid excretion were comparable to those obtained in patient $\mathrm{H}$. $\mathrm{L}$. (Case 2.) The pre-treatment level was very definitely subnormal.

\section{DISCUSSION}

\section{Effect of thyroid hormone on nitrogen metabolism}

The inter-relationships existent or thought to be existent between the thyroid hormone and nitrogen metabolism are very complex, and will be enumerated with little or no discussion. In the first place, it was thought (4) that the level of thyroid hormone in the body controlled the amount of "deposit protein". This contention and the validity of the concept of "deposit protein" itself will not be considered further here. Secondly, the thyroid hormone is intimately connected with growth and hence nitrogen retention. Finally, as regards the data here presented, the most pertinent fact is that most patients with thyrotoxicosis exhibit a loss of body protein. It is almost certain that this loss is connected with the increased energy output. That there is not a specific effect of the thyroid hormone on protein catabolism was well demonstrated by investigators (19) who showed that hyperthyroid patients on high calorie, high carbohydrate, high fat, low protein diets had normal "minimal nitrogen excretions". Presumably, the nitrogen depletion in such cases has resulted from a catabolism of protoplasm at some time during the illness in order to meet the increased energy requirements.

\section{Effect of testosterone compounds on nitrogen metabolism}

Regardless of the cause of this depletion, it is clear from the data in this study that therapy with testosterone propionate overcomes this depletion. It was to be expected that testosterone therapy would cause a positive nitrogen balance in hyperthyroid patients, since it is clearly established that testosterone compounds cause marked nitrogen retention in patients with many other disorders (8 to 12 ). It also seems quite definite that such nitrogen retention indicates the synthesis of protoplasm, inasmuch as phosphorus, potassium, and sulfur are simultaneously retained in approximately the ratios in which these substances are associated with nitrogen in protoplasm (20, 21).

These anabolic effects of testosterone compounds have been established on patients receiving an adequate caloric intake. However, in the present study, the intake of patient P. C. (Case 3) proved to be: $(a)$ adequate in nitrogen, since the patient remained in nitrogen equilibrium during the control periods, but $(b)$ inadequate in calories, since the patient lost weight rapidly during the control periods in spite of the greaterthan-normal caloric content of the diet. The results in this case indicate that testosterone therapy is able to induce anabolism of protoplasm in a patient on an adequate-nitrogen, inadequate-calorie intake. Furthermore, it has been demonstrated that testosterone propionate therapy can reestablish nitrogen equilibrium in an obese individual on an intake inadequate in both nitrogen and calories (21). These findings suggest that testosterone compounds can stimulate anabolism of protoplasm even in the presence of a demand for gluconeogenesis for energy purposes.

\section{Qualitative differences between methyl testo- sterone and testosterone propionate}

The apparently qualitative differences between the effects of testosterone propionate and methyl testosterone on anabolism of protoplasm in thyrotoxicosis are of interest, especially since we have failed to note marked differences of this sort when the two compounds have been used alternately in patients with other clinical syndromes $(20,21)$. The calorigenic properties of methyl testosterone $(8,9,15,16)$ or its effect upon creatine excretion $(9,10,14)$ suggest themselves as factors that may account for these differences.

However, the calorigenic property can probably be dismissed. Certainly in patient H. L. (Case 2 ), the objective and subjective clinical manifestations could not be accounted for on the basis of change in basal metabolic rate. The same may probably be said for patient P. C. (Case 3) although his basal metabolic rate was quite high during and immediately following methyl testosterone administration.

The creatinuria-inducing property of methyl testosterone requires more serious consideration, 
for the amount of nitrogen lost from the body as creatine during the administration of this compound proves to be far too small to account quantitatively for the decrease in protein anabolism that occurred at the same time.

Evidence has been produced (22) which suggests that the creatinuria induced by methyl testosterone probably results from an increased formation of creatine with resultant increased excretion, rather than from an increased excretion of pre-formed creatine. According to one author (23), creatine is formed in the body by the methylation of guanidoacetic acid (glycocyamine), and in this process the methyl groups are supplied by choline and methionine and the guanidoacetic acid from a reaction between glycine and arginine. The formation of creatine at any moment, therefore, depends on the amounts available of choline, and 3 amino acids (glycine, arginine, and methionine); the quantities of these substances, in turn, are governed by two factors: (1) the amounts ingested, and (2) the amounts derived from metabolism of protein, either through increased catabolism or decreased anabolism. Creatine, once it is formed, does not appear to enter into any further chemical reaction involving transfer of nitrogen; it is simply stored in muscle or eliminated in the urine. Any factor which increases creatine in the urine, therefore, tends to deplete the body stores of these 4 substances.

Two of these substances, methionine and arginine, are essential amino acids. It has been shown (24) that a positive nitrogen balance cannot be maintained in the absence of methionine. These findings have subsequently been confirmed (25). Similar experiments (26) have shown that arginine, while not having a pronounced effect on the nitrogen balance, is necessary for maximum growth and normal reproduction. Hence, adequate amounts of methionine and arginine are needed for both protein anabolism and creatine formation; these processes compete, in a sense, for these two amino acids. Creatine, itself not an indispensable food constituent, thus contains an organic chemical grouping indispensable to the body; and loss of creatine through the urine represents loss of material needed for protein anabolism. In hyperthyroidism, the increased energy metabolism and the creatinuria would tend to deplete the stores of methionine and arginine.
In the patients with hyperthyroidism under discussion, methyl testosterone induced sustained creatinuria but only transient protein anabolism. A plausible explanation for the action of methyl testosterone in these patients was advanced recently by Dr. Ephraim Shorr (27). It was suggested that methyl testosterone altered the competition for methionine and arginine between protein anabolism and creatine formation in favor of the latter process, so that as the supply of these amino acids began to run low, creatine formation was maintained at the expense of decreased protein anabolism. Testosterone propionate, on the other hand, by reducing creatine formation, tended to conserve these amino acids for use in protein anabolism.

\section{Calcium metabolism}

We have only fragmentary data on the effect of testosterone propionate on the disordered calcium metabolism characteristic of hyperthyroidism (28). In patient P. C. (Case 3), it should be noted that the high calcium excretion in the urine was reduced under therapy with testosterone propionate. This change will not be discussed until further data have been collected.

\section{Serum potassium}

The serum potassium values in patient $H$. L. (Case 2) are of interest. It will be observed that the value dropped to subnormal levels during testosterone administration (see Figure 2B). This is in accord with recent findings (29). These investigators noted with testosterone therapy a lowering of the serum potassium level without an increase in the urinary potassium excretion and without any clinical manifestations of potassium deficiency; this was in contrast to the hypokalemia and hyperkaluria resulting from desoxycorticosterone acetate administration. Presumably, the testosterone-induced hypokalemia is merely a reflection of the migration of large amounts of potassium into the newly formed protein tissue.

The possible clinical usefulness of testosterone propionate in the management of thyrotoxicosis

Extreme weight loss occasionally occurs in thyrotoxic patients in whom the usual compensa- 
tory appetite increase fails to take place. Such patients probably have depletion of body protein. The finding of liver damage in fatal cases of thyrotoxicosis ( 30 to 32 ) is in accord with the concept that there is a causal relationship between diminished hepatic stores and liver damage (33, 34). A therapeutic agent capable of causing a rapid replacement of such losses should prove of considerable value in the preoperative management of patients with marked wasting. Since testosterone propionate produces no significant depression of the basal metabolic rate, the simultaneous administration of iodine or thiouracil might induce a more favorable response than either agent alone. Patient P. C. (Case 3) does not represent the optimal in such a combination, inasmuch as he had already passed his period of maximal iodine response when testosterone therapy was begun.

Analysis of the nitrogen retention in relation to dosage in patient P. C. (Case 3) (Figure 3A) suggests that $12.5 \mathrm{mgm}$. of testosterone propionate daily produced as great an effect as $100 \mathrm{mgm}$. daily. However, this may not be true, inasmuch as the larger dosages of testosterone propionate were not used until he had already retained a large amount of protein. Had the $100 \mathrm{mgm}$. dosage been used initially, the immediate effect might have been greater. In any event, the definite nitrogen retention induced by $12.5 \mathrm{mgm}$. daily in this very toxic patient suggests that this dosage is adequate.

\section{SUMMARY AND CONCLUSIONS}

1. Since thyrotoxicosis is characterized by an increase in the urinary excretion of nitrogen and creatine, and by a decrease in body weight, and since testosterone propionate has the opposite effect on these 3 variables, studies have been carried out on the metabolic effect of testosterone propionate and methyl testosterone on 3 patients with thyrotoxicosis.

2. In these patients, testosterone propionate induced a markedly positive nitrogen balance and caused a weight gain; these effects were obtained in patients whose diet was constant, and even in individuals whose caloric intake was less than their caloric expenditure.

3. Methyl testosterone had a similar initial effect on the nitrogen balance, but its effect was not sustained; the difference between methyl testosterone and testosterone propionate may possibly be attributed to the calorigenic effect of the former, or more probably to its different effect on creatine metabolism (vide infra).

4. Testosterone propionate decreased the hypercreatinuria which characterizes thyrotoxicosis; methyl testosterone increased it. It is suggested that methyl testosterone may increase creatine formation at the expense of protein anabolism.

5. In the one patient with thyrotoxicosis in whom calcium studies were carried out, there was, with testosterone propionate therapy, a striking reduction in the hypercalciuria characteristic of thyrotoxicosis.

6. The effect of testosterone propionate in reducing the serum potassium level was confirmed in one patient.

7. Testosterone propionate improved the clinical status of the thyrotoxic patients; methyl testosterone, on the contrary, aggravated their toxicity. The latter drug is probably contraindicated in this disease.

8. Testosterone propionate may prove to be a useful therapeutic adjunct in preparing for operation those thyrotoxic patients who have sustained marked weight loss, with emaciation and muscle wasting. A daily dosage of $12.5 \mathrm{mgm}$. is probably adequate. This should be given, of course, in addition to, not in place of, whatever drug is used to reduce the metabolic rate,-iodine or thiouracil.

The authors are grateful to Dr. Fuller Albright and Dr. James $H$. Means for their advice and assistance, and to Miss E. A. MacLachlan for determinations of the serum potassium level.

\section{BIBLIOGRAPHY}

1. Müller, F., Beitrage zur Kenntniss der Basedow'schen Krankheit. Deutsches Arch. f. klin. Med., 1893, 51, 335.

2. Magnus-Levy, A., Ueber Myxödem., Ztschr. f. klin. Med., 1904, 52, 201.

3. Magnus-Levy, A., The Physiology of Metabolism. I: 185-338. Metabolism in Diseases of the Ductless Glands. III : 983-1017. Von Noorden, Metabolism and Practical Medicine. Keener and Company, Chicago, 1907.

4. Boothby, W. M., Sandiford, I., Sandiford, K., and Slosse, J., Effect of thyroxin on respiration and nitrogenous metabolism of normal and myxedematous subjects. I. Method of studying reserve or 
deposit protein with preliminary report of results obtained. Ergebn. Physiol., 1925, 24, 728; Tr. A. Am. Phys., 1925, 40, 195.

5. Byrom, F. B., The nature of myxoedema. Clin. Sc., 1934, 1, 273.

6. Thorn, G. W., Creatine studies in thyroid disorders. Endocrinology, 1936, 20, 628.

7. Tierney, N. A., and Peters, J. P., The mode of excretion of creatine and creatine metabolism in thyroid disease. J. Clin. Invest., 1943, 22, 595.

8. Kochakian, C. D., Testosterone and testosterone acetate, and the protein and energy metabolism of castrate dogs. Endocrinology, 1937, 21, 750.

9. Kenyon, A. T., Sandiford, I., Bryan, A. H., Knowlton, K., and Koch, F. C., The effect of testosterone propionate on nitrogen, electrolyte, water, and energy metabolism in eunuchoidism. Endocrinology, 1938, 23, 135.

10. Howard, J. E., Wilkins, L. and Fleischmann, W., The metabolic and growth effects of various androgens in sexually immature dwarfs. $\mathrm{Tr}$. A. Am. Phys., 1942, 57, 212.

11. Albright, F. A., Parson, W., and Bloomberg, E., Cushing's syndrome interpreted as hyperadrenocorticism leading to hypergluconeogenesis; results of treatment with testosterone propionate. J. Clin. Endocrinol., 1941, 1, 375.

12. Reifenstein, E. C., Jr., The Protein Anabolic Activity of Steroid Compounds in Man. Booklet distributed by Josiah Macy, Jr. Foundation, 1942.

13. Jailer, J. W., The effect of testosterone propionate on creatinuria of experimental hyperthyroidism in male and female monkeys. Endocrinology, 1941, 29, 89.

14. Wilkins, L., Fleischmann, W., and Howard, J. E., Creatinuria induced by methyl testosterone in the treatment of dwarfed boys and girls. Bull. Johns Hopkins Hosp., 1941, 69, 493.

15. McCullagh, E. P., and Rossmiller, H. R., Methyl testosterone-calorigenic activity. J. Clin. Endocrinol., 1941, 1, 503.

16. Byron, C. S., and Katzen, P., Male hypogonadism; clinical effect of the oral use of methyl testosterone in eunuchoidism. J. Clin. Endocrinol., 1941, 1, 359.

17. Folin, O., On the determination of creatinine and creatine in urine. J. Biol. Chem., 1914, 17, 469.

18. Fraser, R. W., Forbes, A. P., Albright, F., Sulkowitch, H., and Reifenstein, E. C., Jr., Colorimetric assay of 17-ketosteroids in urine. J. Clin. Endocrinol., 1941, 1, 234.

19. Lauter, S., and Jenke, M., Ueber den Eiseisstoff wechsel bei verscheidenen Krankheiten. (Versuche uber das N-Minimum bei Diabetes, Carcinom, Leukamie, Bestrahlung, Thyreotoxikose (Basedow), Pneumonie). Deutsches Arch. f. klin. Med., 1925, 146, 323.
20. Albright, F., Cushing's syndrome. Its pathological physiology, its relationship to the adreno-genital syndrome, and its connection with the problem of the reaction of the body to injurious agents ("alarm reaction" of Selye). Harvey Lectures, 1942-1943, Series 38, 123.

21. Reifenstein, E. C., Jr., Albright, F., and Kinsell, L. W., Unpublished data.

22. Wilkins, L., and Fleischmann, W., Personal Communication.

23. Schoenheimer, R. The Dynamic State of Body Constituents. Harvard University Press, Cambridge, 1942.

24. Rose, W. C., Haines, W. J., and Johnson, J. E., The role of the amino acids in human nutrition. J. Biol. Chem., 1942, 146, 683.

25. Albanese, A. A., Holt, L. E., Jr., Brumback, J. E., Jr., Kadji, C. N., Frankston, J. E., and Wangerin, D. M., Nitrogen balance in experimental human deficiencies of methionine and cystine. Proc. Soc. Exper. Biol. and Med., 1943, 52, 18.

26. Holt, L. E., Jr., Albanese, A. A., Shettles, L. B., Kadji, C. N., and Wangerin, D. M., Studies of experimental amino acid deficiency in man. I. Nitrogen balance. Fed. Proc., 1942, 1, 116.

27. Shorr, E., Personal communication.

28. Aub, J. C., Bauer, W., Heath, C., and Ropes, M., Studies of calcium and phosphorus metabolism. III. The effects of the thyroid hormone and thyroid disease. J. Clin. Invest., 1929, 7, 97.

29. Butler, A. M., Talbot, N. B., and MacLachlan, E. A., Effect of testosterone therapy on concentration of potassium in serum. Proc. Soc. Exper. Biol. and Med., 1943, 51, 378. Talbot, N. B., Butler, A. M., and MacLachlan, E. A., Effect of testosterone and allied compounds on the mineral, nitrogen, and carbohydrate metabolism of a girl with Addison's disease. J. Clin. Invest., 1943, 22, 583.

30. Weller, C. V., Hepatic lesions associated with exophthalmic goiter. Tr. A. Am. Phys., 1930, 45, 71.

31. Beaver, D. C., and Pemberton, J. de J., The pathologic anatomy of the liver in exophthalmic goiter. Ann. Int. Med., 1933, 7, 687.

32. Means, J. H., The Thyroid and Its Diseases. J. B. Lippincott Company, Philadelphia, 1937, p. 291292.

33. Ravdin, I. S., Thorogood, E., Riegel, C., and Peters, $R$., The prevention of liver damage, and the facilitation of repair in the liver by diet. J.A.M.A., 1943, 121, 322.

34. Goldschmidt, S., Vars, H. M., and Ravdin, I. S., The influence of the foodstuffs upon the susceptibility of the liver to injury by chloroform; and the probable mechanism of their action. J. Clin. Invest., 1939, 18, 277. 